\title{
Does a Japan-Korea FTA Increase Nitrogen Pollution from Agriculture?: A Nitrogen Balance with the GTAP Model
}

\author{
Yasutaka Yamamoto, ${ }^{*}$ Daisuke Sawauchi* \\ and Kiyotaka Masuda ${ }^{\dagger}$
}

\begin{abstract}
The purpose of this paper is to contribute to the debate over agricultural trade and the environment by asking: Does a Japan-Korea FTA (JKFTA) increase nitrogen pollution from agriculture? In order to contribute to answering the above research question, we measure the potential impact of nitrogen pollution from agriculture caused by agricultural trade liberalization under the JKFTA, using the Global Trade Analysis Project (GTAP) model and the OECD Nitrogen Balance Database. The scenario we model assumes the complete removal of all import tariffs between Japan and Korea, not only in the agricultural sector but in non-agricultural sectors as well. The results show the JKFTA is likely to lead to an overall increase in the total nitrogen surplus for Japan and Korea. Therefore, our results suggest that a JKFTA increases the potential nitrogen pollution from agriculture.
\end{abstract}

Key words : trade and environment, free trade agreement, computable general equilibrium modeling, nitrogen balance, agriculture, Japan, Korea.

\section{Introduction}

The number of regional and bilateral free trade agreements (FTAs) is increasing all over the world. There has been a rapid surge in FTAs in the Asia-Pacific region. Negotiations for a Japan-Korea FTA (JKFTA) - which would be the first among developed countries in Northeast Asia-began in 2003, and six rounds of negotiations were held. However, no negotiations have been held since the end of the sixth round in November 2004. The issue of agricultural trade liberalization, including the removal of import tariffs, is said

\footnotetext{
*Hokkaido University

†University of Shiga Prefecture

An earlier version of this paper was presented at the American Agricultural Economics Association Annual Meeting, Portland, OR, USA, July 29-August 1, 2007. The authors wish to thank Yoshihiro Hosono for his computational assistance and two anonymous reviewers for their constructive comments. Senior authorship is shared.
}

to be one of the reasons why negotiations of the JKFTA have stalled.

The Japanese government seems reluctant to reduce Japan's agricultural trade barriers, because Korea is likely to have a comparative advantage in agricultural production compared to Japan. However, both Japan and Korea have a comparative disadvantage in agricultural production compared to relatively land-abundant developed countries such as the United States and Australia, or relatively labor-abundant developing countries such as China. Therefore, Japan and Korea have been using tariff and non-tariff trade barriers in order to increase domestic producer prices of agricultural products and increase domestic agricultural production. Increased producer prices have led to more intensive agricultural systems in the two countries. The expansion in production and the development of intensive agricultural systems in the two countries have caused concerns over environmental degradation, such as water and atmospheric pollution, due to more manure from livestock 
and more nitrogenous fertilizers used in cropping. Japan's (the fourth-highest) and Korea's (the highest) nitrogen surpluses (kgN/ ha) are quite high among OECD countries (OECD [5]). Much of this large nitrogen surplus will end up in the water environment and contribute to eutrophication.

Whether agricultural trade liberalization will have a positive or negative impact on the natural environment is an empirical matter. Several previous empirical studies sought to quantify the impact of agricultural trade liberalization on environmental pollution from agriculture (Anderson and Blackhurst [1]). There have also been studies on the possible economic and environmental impact of the JKFTA, using the Global Trade Analysis Project (GTAP) model (Hertel [2]). 1) Nakajima [4] measured the likely economic impact caused by the JKFTA. However he did not measure the environmental impact. While Kang and Kim [3] measured both the economic and environmental impact in Korea, using the GTAP model and Korean air pollution inventories, they did not measure the environmental impact in Japan. As far as we know, no attempt has been made to measure the impact of agricultural trade liberalization under the JKFTA on environmental pollution from agriculture in both Japan and Korea.

The purpose of this paper is to contribute to the debate over agricultural trade and the environment by asking: Does a JKFTA increase nitrogen pollution from agriculture? In order to contribute to answering the above research question, we measure the potential impact of nitrogen pollution from agriculture caused by agricultural trade liberalization under the JKFTA, using the GTAP model and the OECD Nitrogen Balance Database (OECD $[5])$.

This paper is organized as follows. In section two, we outline the data and models used in this paper. In section three, we present the simulation results. Finally, in section four we give our conclusions.

\section{Data and Model}

We measure the potential impact of nitrogen pollution from agriculture caused by agricultural trade liberalization under the JKFTA, using the GTAP model and the OECD Nitrogen Balance Database (Rae and Strutt [7,
8]). First, the GTAP model is used to estimate the changes in economic activities, such as agricultural production, caused by the JKFTA. Second, the GTAP results and the OECD Nitrogen Balance Database are used to estimate the potential impact of nitrogen pollution from agriculture caused by the JKFTA.

1) The trade model and liberalization scenario

We use a standard static version of the GTAP model to estimate the potential economic impact of an FTA between Japan and Korea. This model measures the static impact of trade policy changes without incorporating dynamic effects. ${ }^{2}$

Version 5.4 of the GTAP database is used in this analysis. ${ }^{3)}$ It divides the world into 78 regions, each containing 57 sectors or commodities. Since this study focuses on a bilateral FTA between Japan and Korea, the database is aggregated into 24 regions and 14 sectors, as shown in the Appendix (Tables A1 and A-2). This regional aggregation is designed to distinguish the OECD countries, for which nitrogen balances are available, and the non-OECD regions. Three regional groupings of Central and South America, the Rest of Asia and the Rest of the World are used to represent non-OECD countries. Nitrogen balances are not available for these groupings. The commodity aggregation framework is designed to focus on the farm sectors for which nitrogen balances are computed. In terms of the aggregated commodities in the Appendix (Table A-2), the farm sector is defined as commodities from No. 1 (rice) to No. 7 (other livestock).

As seen in Table 1, high tariffs remain on farm and food sectoral commodities in Japan and Korea. The highest Japanese tariffs on imports from Korea are levied on rice (409 $\%)$. Commodities whose tariffs are higher than $50 \%$ in Japan are rice, wheat, cattle and sheep, other meat and dairy products. The highest Korean tariffs on imports from Japan are levied on other crops (304\%). Commodities whose tariffs are higher than $50 \%$ in Korea are cereal grain, other crops and cattle meat.

The scenario we model assumes the complete removal of all import tariffs between Japan and Korea, not only in the agricultural sector but in non-agricultural sectors as well. 
Table 1. Ad valorem tariffs on different commodities on bilateral basis

\begin{tabular}{|c|c|c|}
\hline Commodity & $\begin{array}{l}\text { Japanese tariffs on } \\
\text { imports from Korea }\end{array}$ & $\begin{array}{l}\text { Korean tariffs on } \\
\text { imports from Japan }\end{array}$ \\
\hline Rice & 409 & 5 \\
\hline Wheat & 249 & 3 \\
\hline Cereal grains & 20 & 304 \\
\hline Other crops & 38 & 74 \\
\hline Milk & 0 & 0 \\
\hline Cattle and sheep & 149 & 31 \\
\hline Other livestock & 5 & 10 \\
\hline Cattle meat & 36 & 75 \\
\hline Other meat & 58 & 22 \\
\hline Dairy products & 287 & 26 \\
\hline Other food & 38 & 45 \\
\hline Resource products & 7 & 10 \\
\hline Manufacturing products & 2 & 8 \\
\hline Services & 0 & 0 \\
\hline
\end{tabular}

Source: Derived from Version 5. 4 of the GTAP database.

While it is unlikely that the JKFTA would remove all import tariffs in all sectors between the two countries, this scenario provides an upper bound of the economic impact caused by the possible JKFTA. ${ }^{4)}$

\section{2) The nitrogen model and its linkage to} the trade model

We focus only on nitrogen pollution from agriculture, due to the limitation of available data on other kinds of pollution, such as $\mathrm{SO}_{\mathrm{x}}, \mathrm{NO}_{\mathrm{x}}$, etc. The nitrogen balance is used to estimate the potential changes in nitrogen pollution from agriculture caused by the JKFTA. The nitrogen balance is defined by OECD as the physical difference (surplus/deficit) between nitrogen inputs into, and uptake from, an agricultural system, per hectare of agricultural land (OECD [6]). As shown in Figure 1, the annual total quantity of inputs for the soil surface nitrogen balance includes fertilizer, livestock manure, and other nitrogen inputs. ${ }^{5)}$ The annual total quantity of uptake for the soil surface nitrogen balance includes harvested crops, and forage and pasture.

We use the OECD Nitrogen Balance Database for 1997, corresponding to the base year of version 5.4 of the GTAP database used. This very detailed information is aggregated into a form compatible with the GTAP

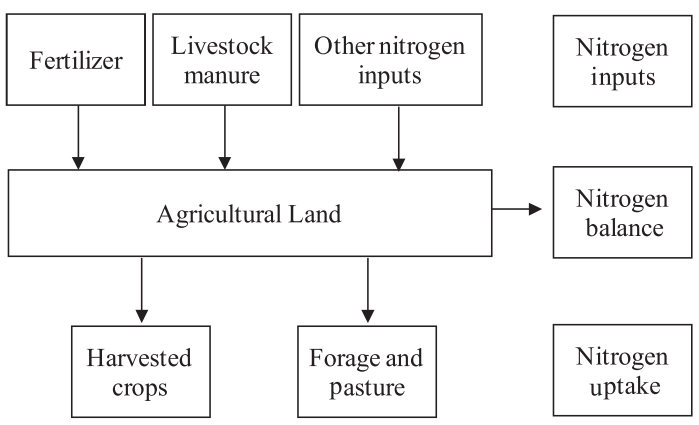

Figure 1. Summary of the OECD nitrogen balance mechanisms

Source: OECD (2001).

Note: Fertilizer means inorganic fertilizer; Livestock manure means net livestock manure; Other nitrogen inputs include biological nitrogen fixation, atmospheric deposition, and seeds and planting materials.

database used. The OECD database includes OECD country data on nitrogen coefficients for crops and livestock.

Nitrogen inputs and uptake are calculated as the relevant quantity of crop outputs ${ }^{6}$ or livestock numbers multiplied by nitrogen coefficients in the OECD Nitrogen Balance Database. We assume that these coefficients will remain constant when trade is liberalized, and that the level of nitrogen inputs and uptake will change by the same propor- 
tion as the levels of crop outputs or livestock numbers. ${ }^{7)}$

We assume that the level of uptake will change by the same proportion as the level of output in each crop sector (Rae and Strutt [8], p. 20). Uptake of nitrogen by forage and pasture consumed is assumed to change from the initial level in proportion to the change in output in livestock number. Data on livestock numbers are taken from the OECD nitrogen database, and these are assumed to change in proportion to changes in the relevant GTAP output variables.

Changes in nitrogen from livestock manure are assumed to occur in proportion to output of each livestock type (Rae and Strutt [8], p. 20). Nitrogen withdrawals due to changes in manure stocks and imports are assumed to maintain the same ratio to livestock manure as in the benchmark database. Nitrogen input from fertilizers is assumed to change in proportion to output of crop sector.

The other important nitrogen input is biological nitrogen fixation by free-living soil organisms on agricultural land and by leguminous crop or pasture (Rae and Strutt [8], p. 21). Since the total agricultural land area does not change in the GTAP model we used, we assume that nitrogen fixation by freeliving organisms remains constant. However, nitrogen fixation by leguminous plants changes in proportion to changes in land use for the other crops sector, appropriate given our aggregation of the GTAP cropping sectors. ${ }^{8)}$

\section{Results}

\section{1) Impact on GDP and farm outputs}

The impact on real GDP and total farm output under full trade liberalization between Japan and Korea is shown in Table 2. ${ }^{\text {g) }}$

Under full trade liberalization, Korea is likely to experience a more substantial gain in real GDP and total farm output than Japan. The impact of full trade liberalization is more observable in total farm output than in real GDP. As shown in Table 2, under full trade liberalization real GDP in Korea expands by $0.21 \%$, whereas real GDP in Japan declines by $0.01 \%$. Total farm output in Korea expands by $2.67 \%$, whereas total farm output in Japan declines by $0.16 \%$.

As shown in Table 3, under full trade liber-
Table 2. Impacts of the JKFTA on real GDP, and total farm output

\begin{tabular}{lcc} 
& & $(\%)$ \\
\hline Real GDP & Japan & Korea \\
Total farm output & -0.01 & 0.21 \\
\hline
\end{tabular}

Notes: 1) All projections are percentage deviations from the initial period.

2) In our paper, output means a monetary value of gross output.

Table 3. Changes in farm sectoral outputs

\begin{tabular}{lrr}
\hline & & $(\%)$ \\
\hline Rice & Japan & Korea \\
Wheat & -0.21 & 6.17 \\
Cereal grains & -0.76 & -0.41 \\
Other crops & -0.50 & -3.18 \\
Milk & 0.00 & -1.47 \\
Cattle and sheep & -0.51 & 9.93 \\
Other livestock & -0.78 & 4.87 \\
\end{tabular}

Notes: 1) All projections are percentage deviations from the initial period.

2) In our paper, outpot means a monetary value of gross output.

alization farm production of most commodities slightly declines in Japan, while output from the livestock sector and the rice sector exhibits some expansion in Korea. In percentage terms, the decline in output from the cattle and sheep sector is the highest $(-0.78 \%)$ in the farm sectoral outputs of Japan. The increase in output from the milk sector is the highest (9.93\%) in the farm sectoral outputs of Korea. Output from the other livestock sector and the rice sector in Korea also expands by $9.08 \%$ and by $6.17 \%$, respectively.

Nakajima [4] estimated the potential economic impact of the JKFTA using the GTAP model and found results similar to ours. His results also show that under full trade liberalization, Korea is projected to experience a more substantial expansion in real GDP and agricultural products than Japan.

2) Impact on nitrogen balances

The impact on nitrogen balance under the full trade liberalization between Japan and Korea is shown in Table 4.

While Japan's nitrogen balance is projected to decrease, the extent of the decrease is 
Table 4. Impacts of the JKFTA on nitrogen balance

$(1,000$ tonnes, \%)

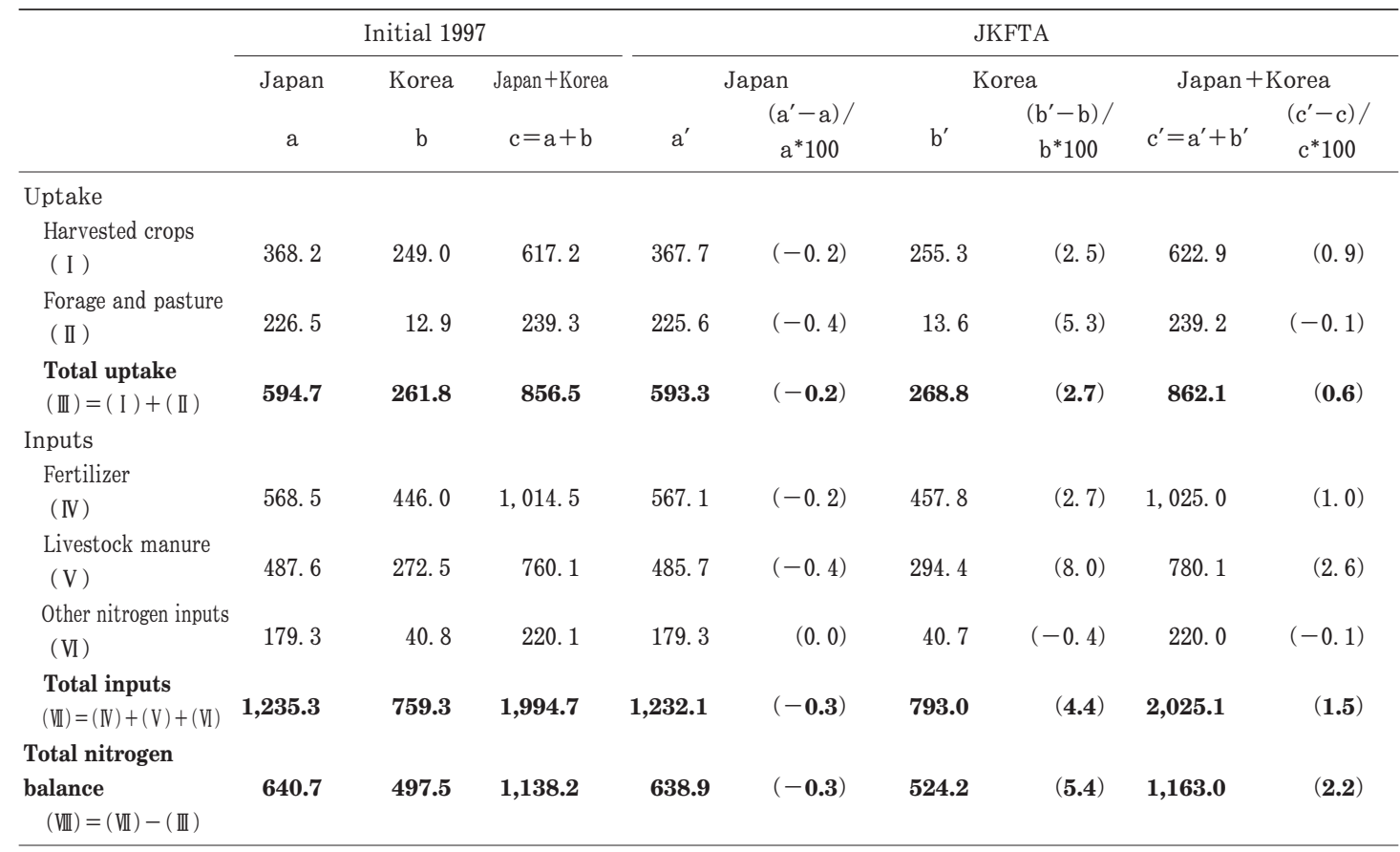

Notes: 1) Figures in parentheses are percentage deviations from the initial period.

2) Fertilizer means inorganic fertilizer; livestock manure means net livestock manure; other nitrogen include biological nitrogen fixation, atmospheric deposition, and seeds and planting materials.

rather small. Japan's nitrogen balance is projected to decrease by only $0.3 \%$ from the initial level of nitrogen surplus. Our results show a decreased level of nitrogen uptake $(0.2 \%)$ and the decrease in nitrogen inputs $(0.3 \%)$ is slightly larger in magnitude. The small decrease in each farm sectoral output results in a small decrease of uptake and inputs, leading to a rather small decrease in Japan's nitrogen balance.

Korea's nitrogen balance is projected to increase by $5.4 \%$ from the initial level of nitrogen surplus. Our results show an increased level of nitrogen uptake $(2.7 \%)$, and the increase in nitrogen inputs $(4.4 \%)$ is much larger in magnitude. The increased inputs from fertilizer and livestock manure are the key driving force behind the anticipated deterioration in the overall nitrogen balance of Korea. This arises mainly due to the large increases in output from the rice sector and the livestock sector. Results comparable to those presented here were reported by Kang and Kim [3]. They analyzed not nitrogen balance but air pollution, such as $\mathrm{SO}_{\mathrm{x}}$ and $\mathrm{NO}_{\mathrm{x}}$ levels in Korea's 26 industry sectors caused by the JKFTA. They used the GTAP model and Korean air pollution inventories to give a quantitative analysis of trade and environmental linkage only in Korea. Their results show Korea's air pollution from the agricultural sector (including the fishing and forest sectors) is projected to increase while overall air pollution from all sectors is projected to decrease.

The total nitrogen balance of Japan and Korea is projected to increase by $2.2 \%$ from the initial level of nitrogen surplus. ${ }^{10)}$ While our results show an increased level of nitrogen uptake $(0.6 \%)$, the increase in nitrogen inputs $(1.5 \%)$ is much larger in magnitude. The increased inputs from fertilizer and livestock manure in Korea are the key driving force behind the anticipated deterioration in the overall nitrogen balance. This arises mainly due to the large increase in outputs from the rice sector and the livestock sector in Korea. 
In sum, our results show the JKFTA is likely to lead to an overall increase in the total nitrogen surplus for Japan and Korea. Therefore, our results suggest that a JKFTA increases the potential nitrogen pollution from agriculture.

\section{Conclusions}

We measure the potential impact of nitrogen pollution from agriculture caused by agricultural trade liberalization under the JapanKorea FTA (JKFTA), using the Global Trade Analysis Project (GTAP) model and the OECD Nitrogen Balance Database. The scenario we model assumes the complete removal of all import tariffs between Japan and Korea, not only in the agricultural sector but in nonagricultural sectors, as well.

The GTAP results show that farm outputs increase significantly in Korea and decrease slightly in Japan. Farm production of most commodities slightly declines in Japan, while outputs from the livestock sector and the rice sector exhibit significant expansion in Korea.

The nitrogen balance results show that the possible JKFTA has a relatively greater impact on the nitrogen pollution from agriculture in Korea than in Japan. The JKFTA is likely to lead to an overall increase in the total nitrogen surplus for Japan and Korea. Therefore, our results suggest that a JKFTA increases the potential nitrogen pollution from agriculture. We think these results and suggestions should be taken into account in the negotiating process of a JKFTA.

However, our results should be treated as preliminary due to inevitable limitations with this kind of research. We briefly raise some issues regarding the further research required. First, we focused only on nitrogenous balance as an indicator of potential pollution from agriculture, due to the limitation of available data. Second, we did not introduce changes of environmental policies in Korea and Japan into our models. Third, we analyzed only national levels of potential pollution. The analysis on local levels of potential pollution from agriculture will also be required because both national and local levels of analyses are necessary in order to know whether agricultural trade liberalization will reduce or increase pollution from agriculture totally.
1) Suzuki [9] measured both the economic and environmental impact in Japan caused by JKFTA, using the partial equilibrium model. However he did not measure the environmental impact in Korea.

2) The standard static version of the GTAP model we use cannot incorporate the dynamic effects of capital accumulation and dynamic productivity gains arising from greater import competition over time.

3) The benchmark of the GTAP database version 5.4 is the year 1997. Of course while it is desirable to use the most recent data available, the lack of data on nitrogen balance of the year 2001 prevented us from using version 6 of the most recent GTAP database (the benchmark: year 2001).

4) While our results from the less liberal scenario are not shown in detail here due to space limitations, the magnitude of changes for farm outputs and the nitrogen balances are smaller than the results from the full trade liberal scenario.

5) In our paper, fertilizer means inorganic fertilizer; livestock manure means net livestock manure; other nitrogen inputs include biological nitrogen fixation, atmospheric deposition, and seeds and planting materials.

6) In our paper, output means a monetary value of gross output.

7) See Rae and Strutt [7, 8] for a detailed description of the nitrogen model and its linkage to the GTAP model.

8) Other sources of nitrogen inputs include atmospheric deposition of nitrogen, nitrogen from recycled organic matter and nitrogen contained in seeds and planting material (Rae and Strutt [8], endnotes 14, p. 20). In the absence of better information, these are assumed constant with changes in trade policies.

9) While our results for countries other than Japan and Korea are not shown in detail here due to space limitations, the magnitude of changes on GDP and farm outputs are smaller than the results for Japan and Korea.

10) The JKFTA is likely to lead to not only a significant overall increase in the total nitrogen balance for Japan and Korea, but also a slight overall increase in the total nitrogen balance for all OECD countries Our results show total nitrogen balance for OECD countries increases by $0.03 \%$.

\section{References}

[1] Anderson, K. and R. Blackhurst, eds. The Greening of World Trade Issues. Ann Arbor: University of Michigan Press, 1992.

[2] Hertel, T. W., ed. Global Trade Analysis: 
Modeling and Applications. Cambridge: Cambridge University Press, 1997.

[3] Kang, S. I. and J. J. Kim. “ A Quantitative Analysis of the Environmental Impact Induced by Free Trade between Korea and Japan," $\mathrm{Pa}$ per presented at the 7th Annual Conference on Global Economic Analysis, Washington D. C., June 17-19. Available at https://www. gtap. agecon. purdue. edu/ resources / download / 1780 . pdf. (last access 15 December 2006), 2004.

[4] Nakajima, T. “An Analysis of the Economic Effects of Japan-Korea FTA : Sectoral Aspects, "Journal of Econometric Study of Northeast Asia, Vol. 4, 2002, pp. 47-62.

[5] OECD. OECD Nitrogen Balance Database. Paris: OECD. Available at http://www. oecd. org/dataoecd/27/63/1890219. exe. (last access 15 December 2006), 2001.

[6] OECD. Environmental Indicators for Agriculture: Volume 3 Methods and Results. Paris: OECD, 2001.
[7] Rae, A. N. and A. Strutt. “Agricultural Trade Reform and Environmental Pollution from Livestock in OECD Countries, " Paper presented at the 45 th Annual Conference of New Zealand Association of Economists, Wellington, 30 June-2 July. Available at http://econ. massey. ac. nz/caps/RaeStruttNZAE04. pdf. (last access 15 December 2006), 2004.

[8] Rae, A. N. and A. Strutt. "The WTO, Agricultural Trade Reform and the Environment: Nitrogen and Agro-chemical Indicators for the OECD," Estey Centre Journal of International Law and Trade Policy, Vol. 8, 2007, pp. 11-36.

[9] Suzuki, N. "WTO, FTA no Chouryuu to Nougyou: Aratana Kouzu wo Tenbou (New Perspectives on Treatment of Agriculture in the WTO and FTAs)," Nougyou Keizai Kenkyuu (Journal of Rural Economics), Vol. 79, 2007, pp. 49-64.

(Received September 19, 2007; accepted February 15, 2009)

\section{Appendix}

Table A-1. Regional aggregation

\begin{tabular}{|c|c|c|}
\hline No. & Aggregated region & GTAP region \\
\hline 1 & Japan & Japan. \\
\hline 2 & Korea & Korea. \\
\hline 3 & Australia & Australia. \\
\hline 4 & New Zealand & New Zealand. \\
\hline 5 & USA & United States. \\
\hline 6 & Canada & Canada. \\
\hline 7 & Mexico & Mexico. \\
\hline 8 & Austria & Austria. \\
\hline 9 & Belgium & Belgium. \\
\hline 10 & Denmark & Denmark. \\
\hline 11 & France & France. \\
\hline 12 & Germany & Germany. \\
\hline 13 & Greece & Greece. \\
\hline 14 & Ireland & Ireland. \\
\hline 15 & Italy & Italy. \\
\hline 16 & Netherlands & Netherlands. \\
\hline 17 & UK & United Kingdom. \\
\hline 18 & Other EU countries & Finland; Luxembourg; Portugal; Spain; Sweden. \\
\hline 19 & Central Europe & Czech Republic; Hungary; Poland; Slovakia. \\
\hline 20 & EFTA & Switzerland; Rest of Eur. Free Trade Area. \\
\hline 21 & Turkey & Turkey. \\
\hline 22 & Rest of Asia & $\begin{array}{l}\text { China; Hong Kong; Taiwan; Indonesia; Malaysia; Philippines; Singa- } \\
\text { pore; Thailand; Vietnam; Bangladesh; India; Sri Lanka; Rest of } \\
\text { South Asia. }\end{array}$ \\
\hline 23 & Central and South America & $\begin{array}{l}\text { Central America, Caribbean; Colombia; Peru; Venezuela; Rest of An- } \\
\text { dean Pact; Argentina; Brazil; Chile; Uruguay; Rest of South America. }\end{array}$ \\
\hline 24 & Rest of the World & $\begin{array}{l}\text { Albania; Bulgaria; Croatia; Malta; Romania; Slovenia; Estonia; } \\
\text { Latvia; Lithuania; Russian Federation; Rest of Former Soviet Union; } \\
\text { Cyprus; Rest of Middle East; Morocco; Rest of North Africa; } \\
\text { Botswana; Rest of South Afr. C. Union; Malawi; Mozambique; Tan- } \\
\text { zania; Zambia; Zimbabwe; Other Southern Africa; Uganda; Rest of } \\
\text { Sub-Saharan Africa; Rest of World. }\end{array}$ \\
\hline
\end{tabular}


Table A-2. Commodity aggregation

\begin{tabular}{rll}
\hline No. & Aggregated commodity & GTAP commodity \\
\hline 1 & Rice & Paddy rice. \\
2 & Wheat & Wheat. \\
3 & Cereal grains & Cereal grains n. e. c. \\
4 & Other crops & Vegetables, fruit, nuts; oil seeds; sugar cane, sugar beet; plant-based \\
& & fibers; crops n. e. c. \\
5 & Milk & Raw milk \\
6 & Cattle and sheep & Cattle, sheep, goats, horses. \\
7 & Other livestock & Animal products n. e. c. \\
8 & Cattle meat & Meat: cattle, sheep, goats, horses. \\
9 & Other meat & Meat products n. e. c. \\
10 & Dairy products & Dairy products. \\
11 & Other food & Vegetable oil and fats; processed rice; sugar; food products n. e. c. ; bev- \\
& & erages and tobacco products. \\
12 & Resource products & Wool, silk-worm cocoons; forestry; fishing; coal; oil; gas; minerals n. e. c. \\
13 & Manufacturing products & Textiles; wearing apparel; leather products; wood products; paper prod- \\
& & ucts, publishing; petroleum, coal products; chemical, rubber, plastic \\
& & prods; mineral products n. e. c. ; ferrous metals; metals n. e. c. ; metal \\
& & products; motor vehicles and parts; transport equipment n. e. c. ; elec- \\
& & tronic equipment; machinery and equipment n. e. c. ; manufactures n. e. c. \\
14 & Services & Electricity; gas manufacture, distribution; water; construction; trade; \\
& & transport n. e. c. ; sea transport; air transport; communication; financial \\
& & services n. e. c. ; insurance; business services n. e. c. ; recreation and other \\
& & services; pubAdmin/defence/health/educat; dwellings.
\end{tabular}

Source: Derived from Version 5. 4 of the GTAP database.

Note: n. e.c. stands for not elsewhere classified. 